\title{
VD-PQ; A Velocity-Dependent Viscous Damping Model for Wave-Structure Interaction Analysis
}

\author{
Constantine Michailides
}

check for updates

Citation: Michailides, C. VD-PQ; A Velocity-Dependent Viscous Damping Model for Wave-Structure Interaction Analysis. J. Mar. Sci. Eng. 2021, 9, 175. https://doi.org/ 10.3390/jmse9020175

Academic Editors: Wei-Bo Chen and Mariano Buccino

Received: 10 December 2020

Accepted: 5 February 2021

Published: 9 February 2021

Publisher's Note: MDPI stays neutral with regard to jurisdictional claims in published maps and institutional affiliations.

Copyright: (C) 2021 by the author. Licensee MDPI, Basel, Switzerland. This article is an open access article distributed under the terms and conditions of the Creative Commons Attribution (CC BY) license (https:/ / creativecommons.org/licenses/by/ $4.0 /)$.
Department of Civil Engineering and Geomatics, Faculty of Engineering and Technology, Cyprus University of Technology, Limassol 3036, Cyprus; c.michailides@cut.ac.cy; Tel.: +357-25002396
Abstract: For the analysis and design of coastal and offshore structures, viscous loads represent one of the most influential parameters that dominate their response. Very commonly, the potential flow theory is used for identifying the excitation wave loads, while the viscous damping loads are taken into consideration as distributed drag type loads and/or as linear and quadratic damping loads approximated with the use of motion decay curves of the structure in specific degrees of freedom. In the present paper, is developed and proposed a numerical analysis method for addressing wave-structure interaction effects through a velocity-dependent viscous damping model. Results derived by a computational fluid dynamics model are coupled with a model that uses the boundary element method for the estimation of the viscous damping loads iteratively in every time-step of the analysis. The computational fluid dynamics model solves the Navier-Stokes equations considering incompressible flow, while the second model solves the modified Cummins Equation of motion of the structure in the time domain. Details about the development of the coupling method and the velocity-dependent viscous damping (VD-PQ) are presented. The coupling between the different models is realized through a dynamic-link library. The proposed coupling method is applied for the case of a wave energy converter. Results derived with the use of the developed numerical analysis method are compared against experimental data and relevant numerical analysis predictions. The importance of considering the instantaneous velocity of the structure in estimating the viscous damping loads is demonstrated. The proposed numerical analysis method for estimating the viscous damping loads provides good accuracy compared to experimental data and, at the same time, low computational cost.

Keywords: wave-structure interaction; viscous damping loads; hydrodynamic analysis; VD-PQ method; linear and quadratic damping; wave energy converters

\section{Introduction}

Renewables represent the largest source of energy and are set to penetrate the global energy system more quickly than any fuel in human history; offshore wind turbines are contributing significantly to this growth and is expecting to dominate into renewables up to 2040 [1]. However, since the higher energy wind resource exists in deep-sea areas (approximately deeper than $70 \mathrm{~m}$ ), the development of floating wind turbines in deep seas has been targeted. Different floating support platforms are possible for use with offshore wind turbines $[2,3]$. On the other hand, the wave energy converters (WECs) technology is in the pre-commercialization phase. Most of the types of the WECs are designed to operate and produce power close to their resonance in different degrees of freedom since large amplitudes in motions result in larger produced power [4]. In addition to marine renewable energy structures, the offshore oil and gas structures are still being developing at a growing rate. A huge development of coastal and offshore energy structures and systems is expected for the years to come in different energy technologies. Analysis and design methods covering the whole life-cycle range of coastal and offshore energy structures are continuously redeveloped and reassessed. Analysis and design of coastal and offshore 
energy structures is an equally demanding and challenging task. Accuracy of the calculated response is required at a maximum level [5], while the computational cost is very important, especially when we approach the design phase of a coastal and offshore energy structure and analysis for many operational and extreme environmental conditions is required to be performed. Unfortunately, the response calculation accuracy contradicts the computational cost (Figure 1). Wave-structure interaction effects and resulting excitation wave loads should be appropriately addressed with rationality but within the limitations of computational capacity and cost. It will be ideal if numerical methods with low computational cost and larger fidelity can be used in the design phase of marine energy structures, but with higher accuracy results.

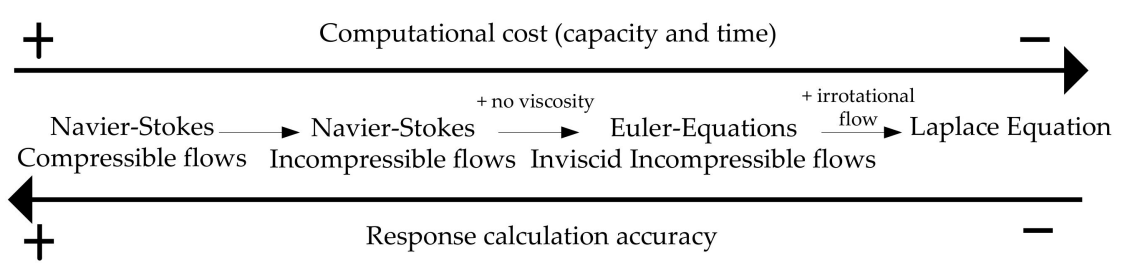

Figure 1. Contradiction between response calculation accuracy and computational cost.

For the analysis and design of coastal and offshore energy structures, wave loads and rest hydrodynamic coefficients are commonly calculated by using potential flow theory [6]. Assumptions of inviscid fluid, incompressible and irrotational flow and small amplitude oscillations are adopted with the potential theory that makes the physical problem under study linear. The aforementioned assumptions are challenged by real sea nonlinear hydrodynamic conditions (e.g., vortex shedding, resonance, viscous drag, flow separation) that are not addressed by the potential flow theory. The calculated wave loads and rest hydrodynamic coefficients are used as input from finite element model tools for the solution of the equation of motion of a floating structure, and consequently, for its analysis and design. This method is very frequently applied in marine structure designs since low computational cost (capacity and time) is required. For the design of WECs, potential flow theory has been used and reported in [7-10]. Usually and when the potential flow theory is adopted for the analysis and design of WECs, in order to consider viscous effects during analysis, distributed drag type loads are added [11-13].

Alternatively, viscous damping effects for a specific motion of a floating structure can be simulated with linear and quadratic damping coefficients that can be calculated with the use of free decay curves. The free decay curves can be generated by experimental tests or by the use of a computational fluid dynamics (CFD) model. In [6] and [14], different mathematical methods for calculating the linear and quadratic coefficients are proposed with the use of decay curves. The PQ method [14] has been applied for the case of a semi-submersible wind turbine [15], while the method proposed in [6] has been used for a heaving type WEC [16], both with efficient results. It is noted that for both methods, a constant value of the linear and quadratic coefficients is used during the analysis of the floating structure in the time domain irrespectively of the velocity of the structure.

On the other hand, the modeling of the dynamics of the fluid flow with the use of CFD methods provides high fidelity accuracy and calculation of the excitation wave loads but is still considered to be relatively computationally expensive, especially when a big number of analyses for different type of environmental loadings are required. CFD analysis is the most powerful tool and a mainstream method that can be used for the analysis of different types of WECs. Up to today, CFD methods and tools have been used successfully for the analysis of different types of WECs, providing robust and reliable results. The required extensions that should be used with the CFD toolbox OpenFOAM in order to simulate efficiently oscillating wave surge converters are discussed in [17]. In [18], a CFD based numerical wave tank model has been developed for the validation study of the 1:5 scale Wavestar point-absorber WEC by including the power-take-off the system in the CFD 
model. The required process of coupling a high-fidelity power-take-off model with a CFDbased numerical wave tank for performing a robust wave-to-wire simulation is discussed in [19]. The validation of the numerical model of the 1:20 scale Wavestar WEC considering different test cases of increasing complexity is presented in [20]. In addition, in [21], a CFDbased model is coupled with different control strategy systems (active and passive) in order to examine the performance of a three-dimensional oscillating wave surge WEC. Many critical steps have been accomplished, but further research work should be made towards the modeling of different components of WECs with CFD-based models [22,23]. Viscous damping loads are very important for the analysis of WECs and should be accounted in the relevant analysis.

For the analysis and design of WECs, viscous loads may be accounted in wavestructure interaction problems as constant loads when the potential flow theory is adopted. In the present paper, a process for accounting viscous damping loads during the analysis of WECs in the time domain is developed and presented. The velocity-dependent viscous damping model (VD-PQ) for wave-structure interaction analysis is proposed. The model is realized through a Dynamic-link library that is coupling the different numerical models. The importance of considering the instantaneous velocity of the structure in estimating the viscous damping loads for every time-step of the analysis is demonstrated through comparisons of RAOs of motions of a WEC in two degrees of freedom against experimental data. VD-PQ is generic, provides good accuracy compared to experimental data and, at the same time, low computational cost, especially when dealing with specific types of analysis (e.g., full long-term analysis).

\section{Description of the Numerical Analysis Method}

The numerical analysis method used in the present paper is generic and can be used for any possible design of coastal and offshore floating structures. The required information that is needed as input in order for the method to be used is a decay curve of the structure for a specific degree of freedom calculated either with the use of a CFD model or with the use of relevant experimental data. CFD or experiments are considered equally reliable and accurate, and their possible uncertainties are out of the scope of the present paper. In the present paper, the decay curves of two motions of the WEC are calculated with the use of a CFD model.

The numerical analysis method of the present paper consists of: (a) a 3D numerical model based on potential theory (PTM) capable for the calculation of linear hydrodynamic coefficients (added mass, radiation damping, excitation loads) in the frequency domain, (b) a 3D computational fluid dynamics model (CFDM) capable for the calculation of decay curves of the oscillation of the floating structure in specific degrees of freedom, (c) a numerical analysis process (NAP) capable for the calculation of velocity-dependent linear and quadratic viscous damping coefficients in every time-step of the solution of the equation of motion and (d) a 3D model (FEM) capable for the solution of the equation of motion of the structure in the time domain and the estimation of the response of all components of the structure and wave field, as well. PTM and CFDM are participating statically during the numerical analysis since specific outputs derived with their use are utilized as input by the FEM and NAP. FEM and NAP are directly coupled, and in every time-step of the analysis, NAP calculates and provides the velocity-dependent viscous damping values that are used for the solution of the equation of motion of the structure. In Figure 2, an outline and coupling interconnections between the different models utilized are presented. 


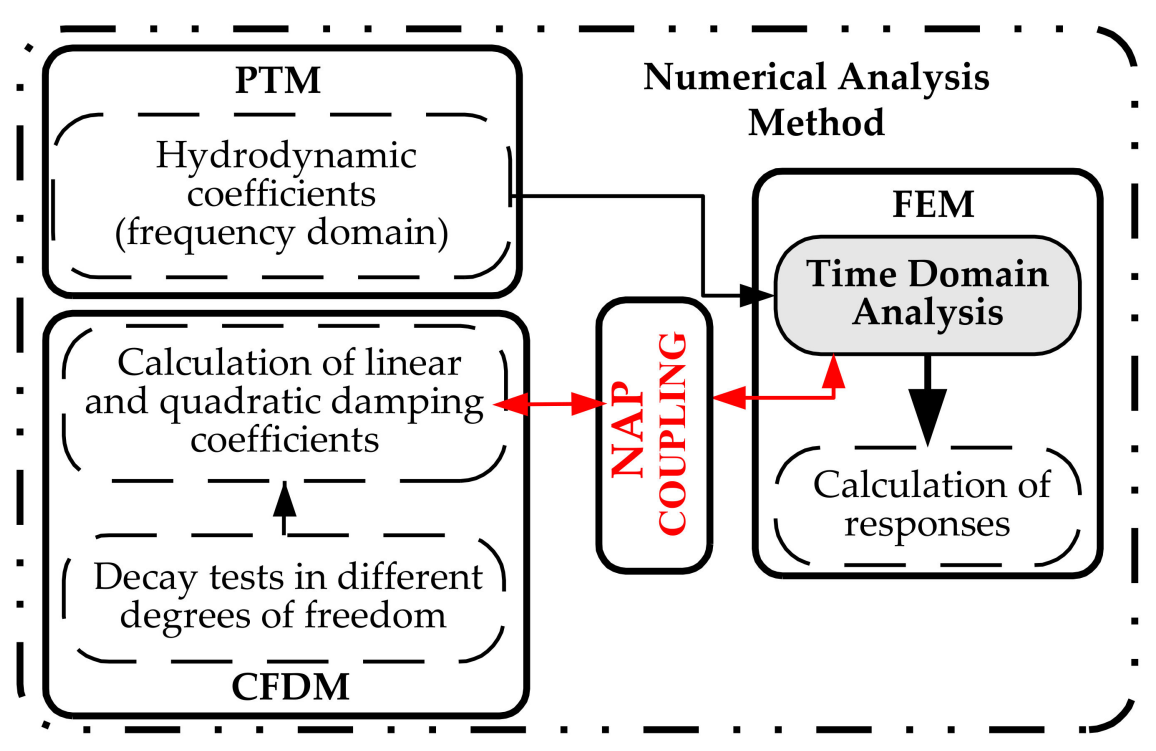

Figure 2. An outline and interconnections of the proposed numerical analysis method.

A description of the different models used in the present paper is presented below. Initially, a PTM is used in order the linear hydrodynamic coefficients of the floating structure under study to be calculated. Those hydrodynamic coefficients are the added mass, radiation damping and excitation wave loads. All the hydrodynamic coefficients are calculated for a specific grid of the wet surface panels of the floating structure and after an appropriate grid size study. Furthermore, the hydrostatic stiffness is calculated. The flow is assumed irrotational and incompressible, and the fluid inviscid while its motion can be described with the use of the velocity potential. The velocity potential, $\varphi$, is described as below:

$$
\varphi=\varphi_{D}+\mathrm{i} \omega \sum_{j=1}^{6} \xi_{j} \varphi_{j}=\varphi_{0}+\varphi_{S}+\mathrm{i} \omega \sum_{j=1}^{6} \xi_{j} \varphi_{j}
$$

where $\varphi_{0}$ is the potential of the incident waves:

$$
\phi_{0}=\frac{\mathrm{igA}}{\omega} \frac{\cosh [\mathrm{k}(\mathrm{d}+\mathrm{z})]}{\cosh (\mathrm{kd})} \mathrm{e}^{-\mathrm{ik}(\mathrm{X} \cos \beta+\mathrm{Y} \sin \beta)}
$$

where $\varphi_{\mathrm{D}}$ is the diffraction potential, $\varphi_{\mathrm{s}}$ is the scattered potential, $\varphi_{\mathrm{j}}, \mathrm{j}=1, \ldots, 6$, is the radiation potential of each rigid body motion associated with the waves that are radiated due to the forced motions of the floating structure, $\omega$ is the wave frequency, $g$ is the gravitational acceleration and $\mathrm{k}$ is the wavenumber. The boundary value problem is solved based on the three-dimensional panel method utilizing Green's theorem, and appropriate boundary conditions are used on the free surface, on the sea bottom and on the floating body. Moreover, the radiation condition for the outgoing waves is adopted [24,25]. With regard to the hydrodynamic coefficients, namely, added mass, $A_{i j}, i, j=1, \ldots, 6$, radiation damping, $B_{i j}, i, j=1, \ldots, 6$, and wave excitation loads, $X_{i}, i=1, \ldots, 6$, those are calculated after the solution of the first-order boundary value problem as below:

$$
\begin{array}{cc}
\mathrm{A}_{\mathrm{ij}}-\frac{\mathrm{i}}{\omega} \mathrm{B}_{\mathrm{ij}}=\rho \iint_{\mathrm{S}_{\mathrm{B}}} n_{\mathrm{i}} \varphi_{\mathrm{j}} \mathrm{d} S \quad \mathrm{i}, \mathrm{j}=1, \ldots, 6 \\
\mathrm{X}_{\mathrm{i}}=-\mathrm{i} \omega \rho \iint_{\mathrm{S}_{\mathrm{B}}} n_{\mathrm{i}} \varphi_{\mathrm{D}} \mathrm{ds} \quad \mathrm{i}=1, \ldots, 6
\end{array}
$$

where $n_{i}, i=1, \ldots, 6$, is the normal component of the $i$-th rigid body mode on the mean body wetted surface, $S_{B}$, and $\rho$ is the water density. As far as the coefficients of the hydrostatic 
stiffness matrix, $C_{i j}, i, j=1, \ldots, 6$, those are calculated with the use of the following equation:

$$
\mathrm{C}_{\mathrm{ij}}=\rho \mathrm{g} \iint_{\mathrm{S}_{\mathrm{B}}} \mathrm{n}_{\mathrm{j}}\left(\mathrm{w}_{\mathrm{i}}+\mathrm{dD} \mathrm{D}_{\mathrm{i}}\right) \mathrm{ds}
$$

where $d$ is the draft of the floating structure and $D_{i}$ is the divergence of the motion displacement.

As far as the computational fluids dynamic model, the CFDM is developed in order to solve the Navier-Stokes equations and estimate realistic viscous damping loads in specific degrees of freedom of the structure. By applying an initial displacement on the floating structure in a specific degree of freedom and letting the structure oscillate, the decay curve of this motion is calculated with the use of the CFDM. Incompressible viscous flow is considered by using the following set of equations:

$$
\begin{gathered}
\rho\left(\frac{\partial \mathbf{V}}{\partial \mathrm{t}}+\nabla \cdot(\mathbf{V} \mathbf{V})\right)=-\nabla \mathrm{p}+\nabla \cdot \mu\left(\nabla \mathbf{V}+\nabla \mathbf{V}^{\mathrm{T}}\right)+\rho \mathbf{g}+\mathbf{F} \\
\nabla \cdot \mathbf{V}=0
\end{gathered}
$$

where $\mathbf{V}$ is the velocity of the fluid, $\mathrm{p}$ is the pressure, $\mu$ is the viscosity, $\rho$ is the water density, $\mathbf{g}$ is the gravitational acceleration, and $\mathbf{F}$ represents the force applied due to the presence of the structure in the computational domain. The Navier-Stokes equations are solved in the whole numerical domain on a structured grid by second-order finite volume discretization techniques in space and time. Capturing the free surface of the waves in the two-phase flow problem under study is modeled through the level set method, while water-structure interaction is modeled with the use of the immersed boundary method. The immersed boundary method has been recently adopted in offshore and ocean engineering problems [26-31] for the robust and efficient numerical modeling of physical problems related to the interaction between two fluids and moving rigid structures, unstructured grids, high-density flows, WECs operating in multiple degrees of freedom and water entry/exit problems. In [32-34], the slip boundary condition is imposed on all sides of the numerical domain, and no penetration boundary condition is imposed on the solid-fluid interface. It should be noted that the effect of the modeling details of the CFD model is out of the scope of the present paper. As explained previously, the CFD model should be able to provide the decay curves of the floating structure in specific degrees of freedom with a good level of accuracy.

As far as the third model, the FEM model is developed in order to solve the equation of motion of the floating structure and, consequently, calculate all relevant responses (e.g., motions, the tension of mooring lines). With the use of Newton's second law, the equation of motion of the floating body in the time-domain is as below [35]:

$$
(\mathrm{M}+\alpha(\infty)) \ddot{\mathrm{x}}(\mathrm{t})+\mathrm{B}_{1} \dot{\mathrm{x}}+\mathrm{B}_{2} \mathrm{f}(\dot{\mathrm{x}})+\int_{0}^{\mathrm{t}} \dot{\mathrm{x}} \mathrm{h}(\mathrm{t}-\tau) \mathrm{d} \tau+\mathrm{Cx}(\mathrm{t})=\mathrm{X}(\mathrm{t})
$$

where $\mathrm{M}$ is the structural mass, $\alpha$ is the added mass that corresponds to infinite frequency, $\mathrm{B}_{1}$ and $\mathrm{B}_{2}$ are the linear and quadratic damping coefficients of the hydrodynamic damping, $C$ is the summation of hydrostatic stiffness and mooring lines stiffness, and $X$ is the excitation wave load. It is noted that the hydrodynamic damping can be reproduced accurately with linear and quadratic damping terms. Moreover, $x(t), \dot{x}(t), \ddot{x}(t)$ are the displacement, velocity and acceleration of any translational or rotational degree of freedom of the structure and $h(t-\tau)$ is the retardation function. The calculation of the coefficients of the matrix of the retardation function and the added mass in infinite frequency is not straightforward due to the semi-infinite integral and also due to the possibility of instability for the numerical calculation of the coefficients.

With the use of the CFDM, decay curves are generated for specific degrees of freedom of the floating structure (Figure 3). It is noted that the decay curve in Figure 3 is an example of a possible curve; the cycles of oscillations and rest characteristics depend upon the 
wave-structure interaction of a specific structure. With the use of the data of the decay curve and by following the methods proposed in [14] (PQ method) or in [6] linear, $\mathrm{B}_{1}$, and quadratic, $B_{2}$, damping coefficients can be calculated and inserted in the equation of motion of the floating body in time-domain (Equation (8)). Based on the PQ method [14], successive positive or negative amplitudes of the decay curve in the whole decay time are considered in order to determine the relative decrement of the decay curve. The $B_{1}$ and $B_{2}$ coefficients are calculated with the following equations:

$$
\begin{aligned}
\mathrm{B}_{1} & =2 \mathrm{p} \frac{\mathrm{M}}{\mathrm{T}_{\mathrm{n}}} \\
\mathrm{B}_{2} & =\frac{3}{8} \mathrm{qM}
\end{aligned}
$$

where $\mathrm{p}$ and $\mathrm{q}$ are coefficients calculated with the use of data of the decay curve, $\mathrm{M}$ is the total mass of the floater (e.g., structural mass and added mass in infinite frequency), and $T_{n}$ is the natural frequency of the floater for the examined degree of freedom that we want to calculate the $B_{1}$ and $B_{2}$ coefficients. For the estimation of the $p$ and q coefficients, points with coordinates $\left[\left(\Phi_{i+1}+\Phi_{i}\right) \times 0.5,\left(\Phi_{i}-\Phi_{i+1}\right) /\left(\Phi_{i+1}+\Phi_{i}\right) \times 0.5\right]$ are calculated and plotted where $\Phi$ is the peak amplitude (positive or negative) of the decay curve. A line can be fitted through those points to calculate the intercept ( $p$ value) with the vertical axis and the slope (q value) of the line. Again, it is stated that decay curves can be generated either with the use of a CFD model or with relevant experimental tests; both types of data can be used for the estimation of the $\mathrm{B}_{1}$ and $\mathrm{B}_{2}$ coefficients.

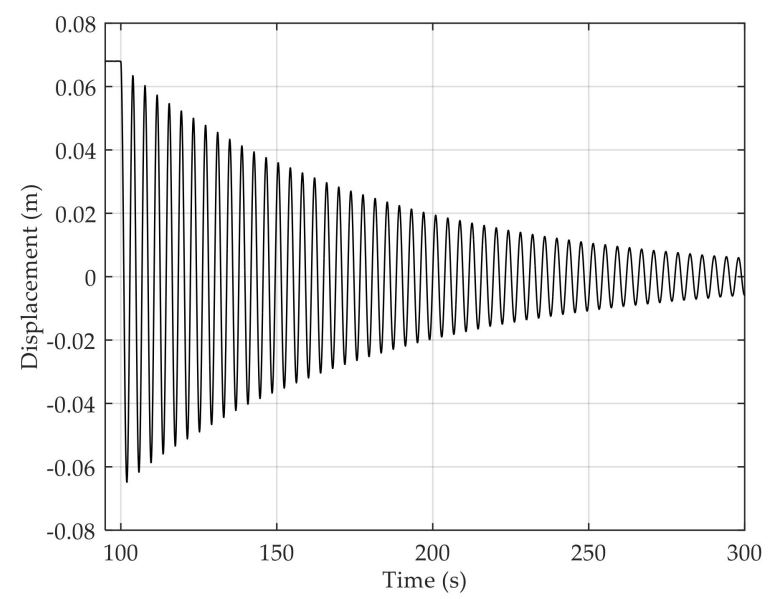

Figure 3. A decay curve of a floating structure in a specific degree of freedom.

If we look carefully at Figure 3 (or any possible decay curve), we can see that at the beginning of the decay curve, the velocity of the structure is large and afterward becomes very small as the number of oscillations increases. For the case where the damping force has a large dependence on the Reynolds number or on the Keulegan-Carpenter number and for the case that the floating structure is not lightly damped, the velocity changes significantly for each subsequent oscillation. For those conditions, the use of constant $B_{1}$ and $B_{2}$ coefficients may be conservative and not representative for the total decay time since $B_{1}$ and $B_{2}$ are calculated considering the whole decay time irrespectively of the velocity of the structure.

In order to take into account the velocity of the floating structure and its effect on the viscous damping, a velocity-dependent viscous damping model (VD-PQ) is developed and used. Depending on the velocity of the floater, different pairs of $B_{1}$ and $B_{2}$ can be used during the analysis (Equation (8)). 
Based on the results of a decay curve, different velocity values, $\dot{x}_{k, \text { decay }}$, of the floater can be calculated as below:

$$
\dot{\mathrm{x}}_{\mathrm{k}, \text { decay }}=\frac{\left|\Phi_{\mathrm{i}}-\Phi_{\mathrm{i}+1}\right|}{\left|\mathrm{T}_{\mathrm{i}}-\mathrm{T}_{\mathrm{i}+1}\right|}
$$

where $\Phi$ is the amplitude of the $\mathrm{i}^{\text {th }}$ peak of the motion (positive or negative) of the decay curve, $\mathrm{T}$ is the relevant time that the $\mathrm{i}^{\text {th }}$ peak occurs, and $\mathrm{k}$ is the total number of positive or negative peaks of the decay curve. Based on all the calculated values of $\dot{x}_{k, \text { decay }}$ the decay curve for a specific degree of freedom, the mean velocity value, $\dot{x}_{k, \text { decay }}^{\mathrm{M}}$, is calculated as below:

$$
\dot{\mathrm{x}}_{\mathrm{k}, \mathrm{decay}}^{\mathrm{M}}=\frac{1}{\mathrm{k}} \sum_{\mathrm{k}=1}^{\mathrm{k}} \dot{\mathrm{x}}_{\mathrm{k}, \text { decay }}
$$

It should be stressed that the $\dot{x}_{k, \text { decay }}$ and $\dot{x}_{k, \text { decay }}^{\mathrm{M}}$ values are calculated with the use of the decay curve data and remain the same during the analysis.

By comparing the velocity of the structure $\dot{x}_{t}$ with the $\dot{x}_{k, \text { decay }}^{\mathrm{M}}$ value, we can define two different velocity regions, $\mathrm{VR}_{1}$ and $\mathrm{VR}_{2}\left(\mathrm{VR}_{1}\right.$ with $\dot{\mathrm{x}}_{\mathrm{t}}<\dot{\mathrm{x}}_{\mathrm{k}, \mathrm{decay}}^{\mathrm{M}}$ and $\mathrm{VR}_{2}$ with $\left.\dot{\mathrm{x}}_{\mathrm{t}}>\dot{\mathrm{x}}_{\mathrm{k}, \mathrm{M} \text { decay }}^{\mathrm{M}}\right)$. It should be stressed that the $\dot{x}_{t}$ value is calculated with the use of Equation (8). For the two different regions, we can calculate with Equations (9) and (10) two different pairs of linear, $\mathrm{B}_{1}^{\mathrm{VR}_{1}}$ and $\mathrm{B}_{1}^{\mathrm{VR}_{2}}$, and quadratic, $\mathrm{B}_{2}^{\mathrm{VR}_{1}}$ and $\mathrm{B}_{2}^{\mathrm{VR}_{2}}$, damping coefficients since two different fitted lines exist in each region. The FEM solver in every time-step of the analysis (Equation (8)) will use one of the two pairs of the linear and quadratic damping coefficients. Depending on the velocity, $\dot{x}_{t}$, of the floater, the pair of $B_{1}$ and $B_{2}$ that corresponds to the correct velocity range, $\mathrm{VR}_{1}$ or $\mathrm{VR}_{2}$, is used in the analysis made by the FEM model. The selection of the correct pair of the damping coefficients is made iteratively in every time-step of the analysis.

At the beginning of the analysis, the pair $\mathrm{B}_{1}^{\mathrm{VR}_{1}}$ and $\mathrm{B}_{2}^{\mathrm{VR}_{1}}$ is assigned as the linear and quadratic damping coefficients. Afterward (this is made for every time-step, $t$, of the analysis), an iteration is made as below in order the correct linear and quadratic damping coefficients pair to be used in every time-step.

For a specific time-step, $t$, the linear and quadratic damping coefficients from the previous time-step, $t-1$, are randomly assigned. With the use of Equation (8) and after appropriate numerical integration techniques, the velocity of the floating structure $\dot{x}_{t, i t 0}(t)$ is calculated, and its value is compared with the mean velocity value, $\dot{\mathrm{x}}_{\mathrm{k}, \text { decay }}$, as calculated by the decay curve (Equation (12)), as below:

$$
\dot{\mathrm{x}}_{\mathrm{t}, \mathrm{it} 0}(\mathrm{t})<\dot{\mathrm{x}}_{\mathrm{k}, \mathrm{decay}}^{\mathrm{M}}
$$

If Equation (13) holds true, then the pair $\mathrm{B}_{1}^{\mathrm{VR}_{1}}$ and $\mathrm{B}_{2}^{\mathrm{VR}}$ is assigned as the linear and quadratic damping coefficients pair, and Equation (8) is solved again, and the new calculated velocity of the floating structure $\dot{x}_{t, i t 1}(t)$ is compared with the $\dot{x}_{k, \text { decay }}^{M}$ as below:

$$
\dot{\mathrm{x}}_{\mathrm{t}, \mathrm{it} 1}(\mathrm{t})<\dot{\mathrm{x}}_{\mathrm{k}, \text { decay }}^{\mathrm{M}}
$$

If Equation (14) holds true, then the $x(t), \dot{x}(t), \ddot{x}(t)$ of the floater are calculated with Equation (8), and the analysis moves to the next time-step, $t+1$. If Equation (13) does not hold true, then the pair $\mathrm{B}_{1}^{\mathrm{VR}_{2}}$ and $\mathrm{B}_{2}^{\mathrm{VR}_{2}}$ is assigned as the linear and quadratic damping coefficients, Equation (8) is solved, and the new calculated velocity of the floater $\dot{x}_{t, i t 2}(t)$ is compared with the $\dot{x}_{k, d e c a y}^{M}$ as below:

$$
\dot{\mathrm{x}}_{\mathrm{t}, \mathrm{it} 1}(\mathrm{t})>\dot{\mathrm{x}}_{\mathrm{k}, \text { decay }}^{\mathrm{M}}
$$

If Equation (15) holds true, then $x(t), \dot{x}(t), \ddot{x}(t)$ are calculated with Equation (8) and the analysis moves to the next time-step, $t+1$. The iterative process that is performed at every 
time-step of the analysis (Equations (8)-(15)) is realized through a Dynamic-link library (DLL) and is coupled with the FEM model for solving Equation (8). In this way, a velocitydependent viscous damping model (VD-PQ) for wave-structure interaction analysis was developed and implemented.

\section{Results and Discussion}

The numerical analysis method that was developed in the present paper was applied for a heaving type WEC. The WEC consists of two rigid bodies connected with two vertical tendons. The first body is a fully submerged horizontal cylinder with domed ends and rectangular-shaped surface piercing columns, while the second one is a fully submerged mass [36,37]. A system of mooring lines is used to keep the WEC in place by providing horizontal and heave stiffness. The predictions of the numerical analysis method were compared with relevant experimental data performed at the Kelvin Hydrodynamics Laboratory in the University of Strathclyde, Glasgow, UK [36]. It is noted that the numerical analysis method was developed for the dimensions and properties of the test model without any upscale. In Figure 4, the examined WEC in the present paper during experiments is presented. Images of the different numerical models, namely, the PTM, CFDM and FEM, that were developed and used for the purposes of the present paper are presented in Figure 5. It is noted that the details and rest characteristics of the components of WEC as presented in Table 1 and [36]. For both the PTM and CFDM models grid convergence study was performed for selecting the final grid mesh; more details can be found in [16]. The FEM model is a multi-body model consisting of two rigid bodies, cylinder and mass, which are connected with vertical tendons. The second rigid body is a mass and is modeled as a point mass. Hydrodynamic effects of the second rigid body are ignored, as well as the hydrodynamic interaction between the two rigid bodies. The two bodies are free to undergo all possible motions (three translational and three rotational).

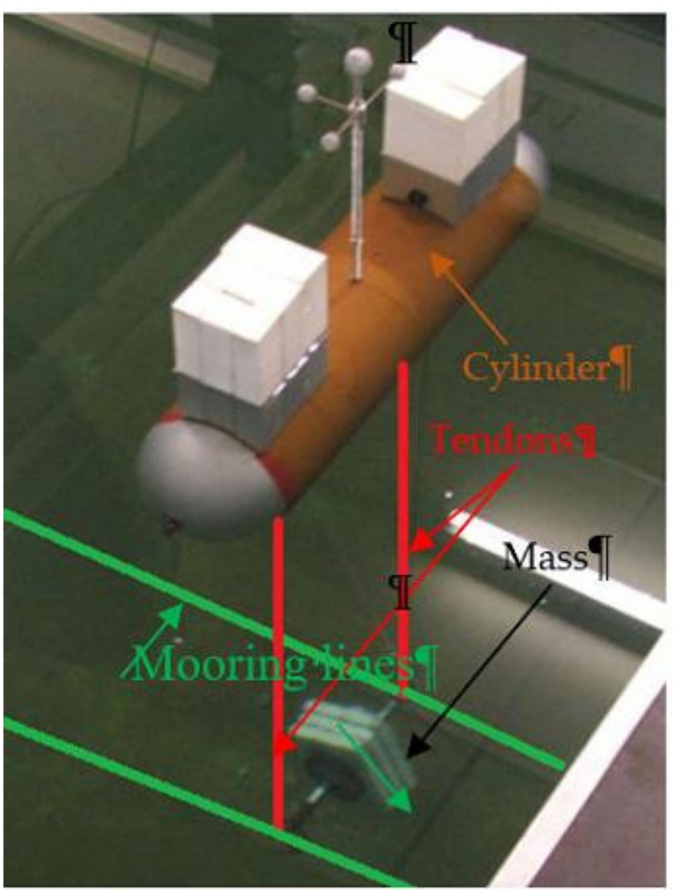

Figure 4. The examined WEC during experiments. 


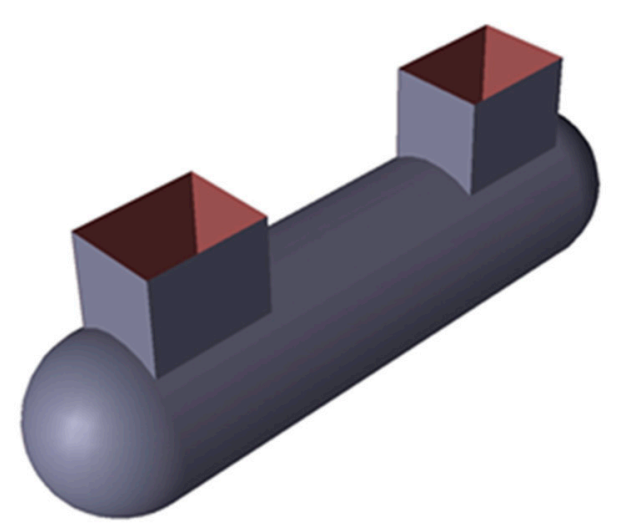

(a)

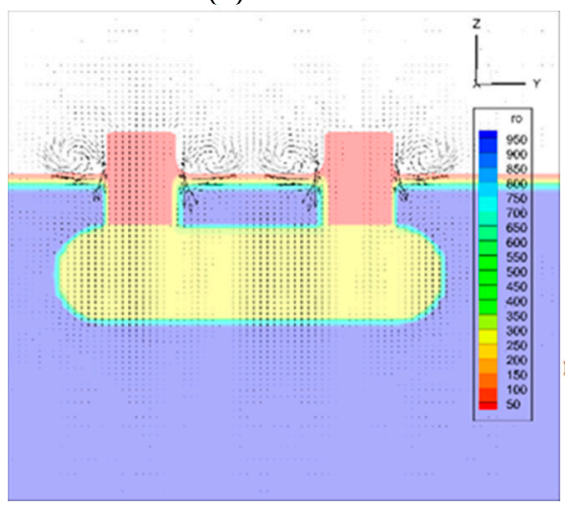

(c)

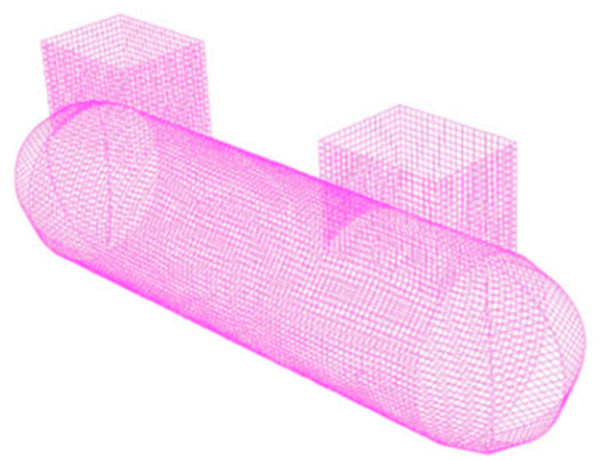

(b)

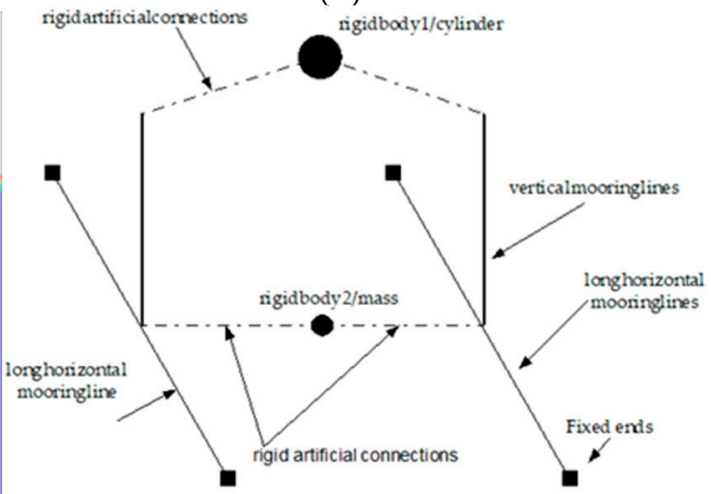

(d)

Figure 5. Developed numerical models used for the examined WEC: (a) potential theory (PTM) numerical model (Equations (1)-(5)), (b) panel discretization of the wet surface of the PTM model, (c) CFDM for decay curves calculation (Equations (6)-(7)) and (d) 3D model of the WEC (Equation (8)).

Table 1. Design characteristics of the examined wave energy converters (WEC).

\begin{tabular}{ccccc}
\hline Displacement & $\mathbf{0 . 0 2 7} \mathbf{~ m}^{\mathbf{3}}$ & Length of Each Vertical Mooring Line & $\mathbf{1 . 3} \mathbf{~ m}$ & $88.35 \mathrm{~N}$ \\
\hline Structural mass & $8.9 \mathrm{~kg}$ & Tension of each vertical mooring line & $36.30 \mathrm{~N} / \mathrm{m}$ \\
\hline Weight of clump mass & $-19.75 \mathrm{~kg}$ & Heave stiffness of mooring lines & $129.1 \mathrm{~N} / \mathrm{m}$ \\
\hline Cylinder diameter & $0.2 \mathrm{~m}$ & Surge stiffness of mooring lines & $0.112 \times 0.15 \mathrm{mxm}$ \\
\hline Submergence of centerline of cylinder & $0.2 \mathrm{~m}$ & Rectangular dimensions of piercing columns & 0.06 \\
\hline
\end{tabular}

With the use of the CFDM, the decay curves of the heave and surge motions of the first rigid body are calculated and presented in Figure 6. The in-house CFD tool developed by $[32,33]$ was used for the estimation of the decay curves in surge and heave. The heave natural frequency of the WEC predicted by the CFDM is $\mathrm{T}_{\text {heave }}=2.28 \mathrm{sec}$, while the surge natural period is $\mathrm{T}_{\text {surge }}=3.87 \mathrm{sec}$. Based on the decay curves, the mean velocity value $\dot{\mathrm{x}}_{\mathrm{k}}^{\mathrm{M}}$ is $12.62 \mathrm{~mm} / \mathrm{sec}$ and $3.41 \mathrm{~mm} / \mathrm{sec}$ for heave and surge, respectively. For every motion and based on the peak (positive and negative) values, $\Phi$, of the decay curves, points with coordinates $\left[\left(\Phi_{\mathrm{i}+1}+\Phi_{\mathrm{i}}\right) \times 0.5,\left(\Phi_{\mathrm{i}}-\Phi_{\mathrm{i}+1}\right) /\left(\Phi_{\mathrm{i}+1}+\Phi_{\mathrm{i}}\right) \times 0.5\right]$ are calculated and plotted for the two different velocity ranges compared to the mean velocity value $\dot{x}_{k}^{M}$. Two lines are fitted through those points that correspond to the two different velocity regions $\mathrm{VR}_{1}$ and $\mathrm{VR}_{2}$. The $\mathrm{p}$ and $\mathrm{q}$ values for the two lines for every motion are calculated with the PQ method and are presented in Table 2. The $\mathrm{p}$ and $\mathrm{q}$ values are used for the calculation of the linear and quadratic damping coefficients and consequently are used for the solution of the equation of motion of the WEC (Equation (8)). 


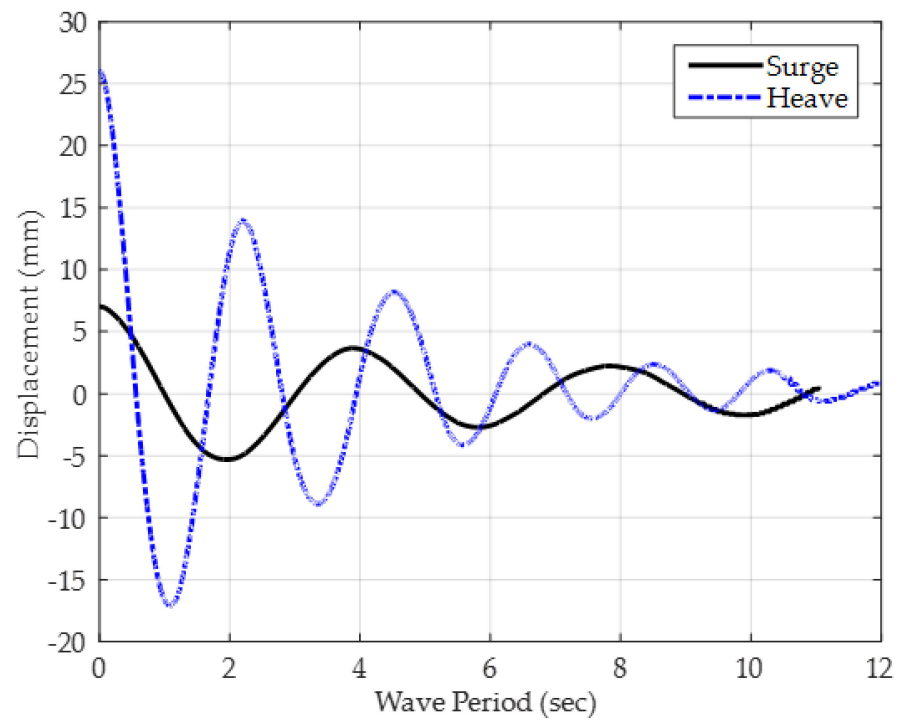

Figure 6. Decay curves for surge and heave motions of rigid body 1 with the use of the computational fluid dynamics model (CFDM).

Table 2. $\mathrm{p}$ and $\mathrm{q}$ damping coefficients for the examined motions and two different velocity regions $\mathrm{VR}_{1}$ and $\mathrm{VR}_{2}$.

\begin{tabular}{cccc}
\hline Motion. & Velocity Range & Linear Damping Coefficient, $\mathbf{p}$ & Quadratic Damping Coefficient, $\mathbf{q}$ \\
\hline \multirow{2}{*}{ Surge } & $\mathrm{VR}_{1}$ & 0.2074 & 0.7118 \\
\cline { 2 - 4 } & $\mathrm{VR}_{2}$ & 0.1018 & 0.7122 \\
\hline \multirow{2}{*}{ Heave } & $\mathrm{VR}_{1}$ & 0.5005 & 0.0059 \\
\cline { 2 - 4 } & $\mathrm{VR}_{2}$ & 0.4593 & 0.0359 \\
\hline
\end{tabular}

With the use of the VD-PQ damping coefficients for both velocity ranges, analysis is performed for regular waves with different wave periods and heights in order the RAOs of the heave and surge motions to be calculated. Three different wave heights were examined equally to $12 \mathrm{~mm}, 25 \mathrm{~mm}$ and $75 \mathrm{~mm}$. Similarly, analysis is performed for the case where only the radiation damping calculated by potential theory is used. The numerical analysis predictions from the two different models are compared against experimental data as reported in [36]. In Figures 7 and 8, comparisons of heave and surge of the first rigid body of the examined WEC between experimental data and numerical predictions are presented. The predictions are calculated with the use of the FEM model with the developed iterative viscous damping VD-PQ and with the use of radiation damping. For both damping models, the results follow the trends of the relevant experimental data with differences. For heave motion and irrespectively of the examined wave height, the use of the VD-PQ model results in RAOs values closer to the experimental data compared to the case that the radiation damping is only used during the analysis. This is more intense for examined wave periods in the wave period range close to the natural period in heave, $T_{\text {heave }}=2.28 \mathrm{sec}$, where the model that uses only the radiation damping completely fails to predict the response. VD-PQ results to very efficient results for predicting the response of the WEC especially close to the resonance of the body. On average, the relative difference between numerical predictions and experimental data is $8.41 \%$ and $43.25 \%$ for VD-PQ and radiation potential models, respectively. Especially for examined wave periods close to the heave resonance of WEC, the model which uses only radiation damping results to unrealistic predictions that are up to four times larger than the experimental data values. Similar observations can be found as far as the RAOs of the surge motion. The use of the VD-PQ model results in a better estimation of the responses in all the examined wave periods and especially close to the resonance of the WEC in the surge $\left(\mathrm{T}_{\text {surge }}=3.87 \mathrm{sec}\right)$. The relative difference for surge motion is $6.85 \%$ and $20.72 \%$ for VD-PQ and radiation potential models, respectively. Based 
on the results, it is clear that a correction of the viscous damping model should take place when studying WECs since WECs operate close to theirs.

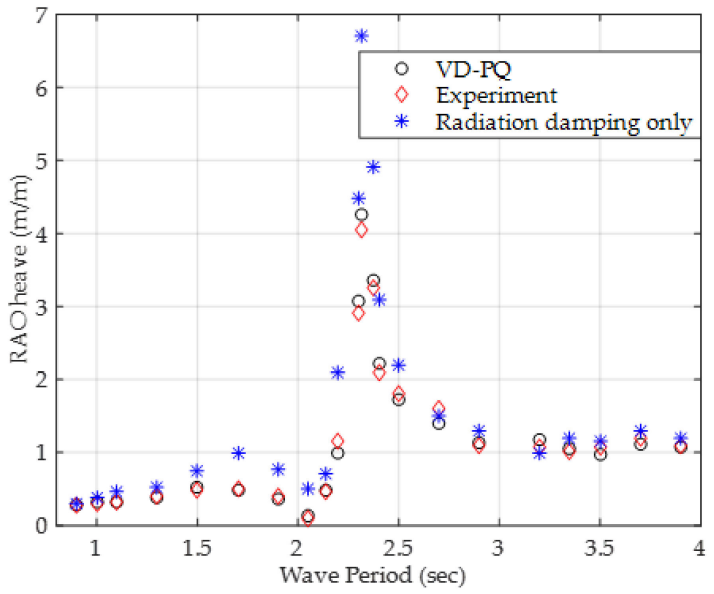

(a)

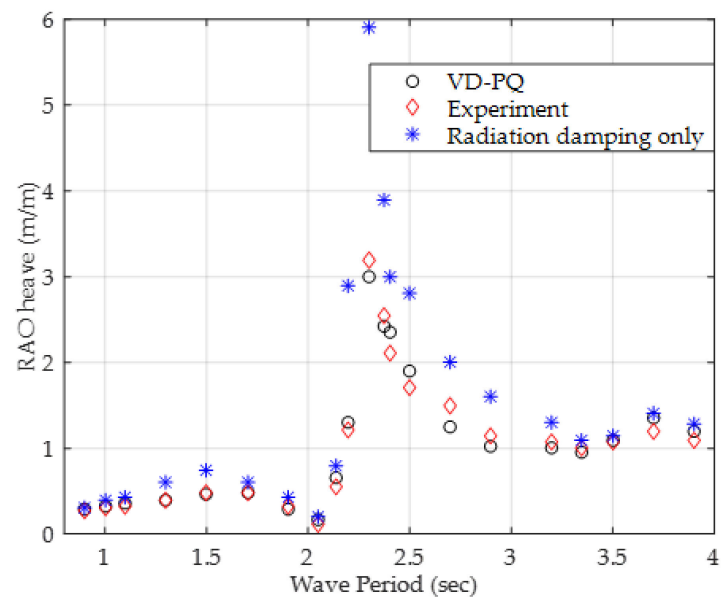

(b)

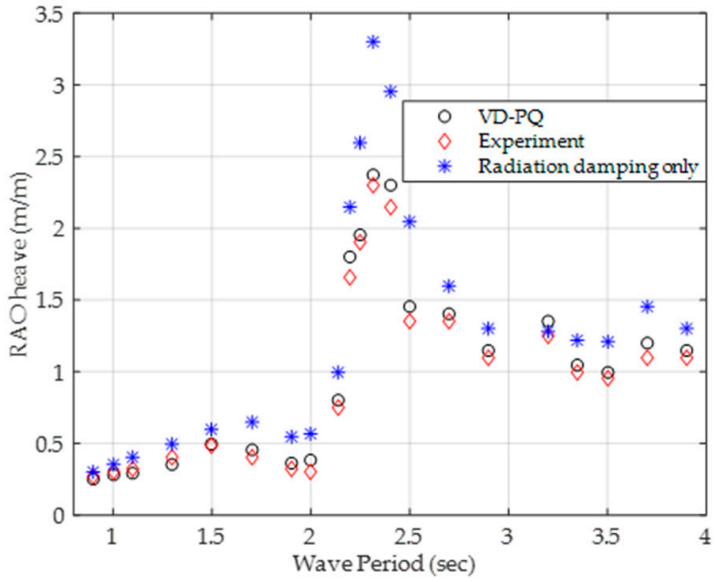

(c)

Figure 7. Comparison of heave motion of the examined WEC between experimental data and predictions with use of the velocity-dependent viscous damping model (VD-PQ) and with use of potential theory damping for (a) wave height equal to $12 \mathrm{~mm}$, (b) wave height equal to $25 \mathrm{~mm}$ and (c) wave height equal to $75 \mathrm{~mm}$. 


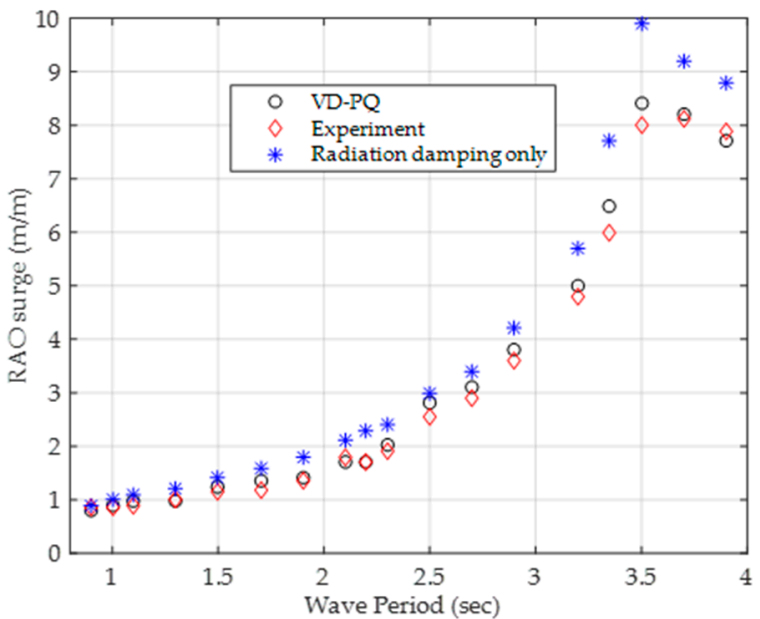

(a)

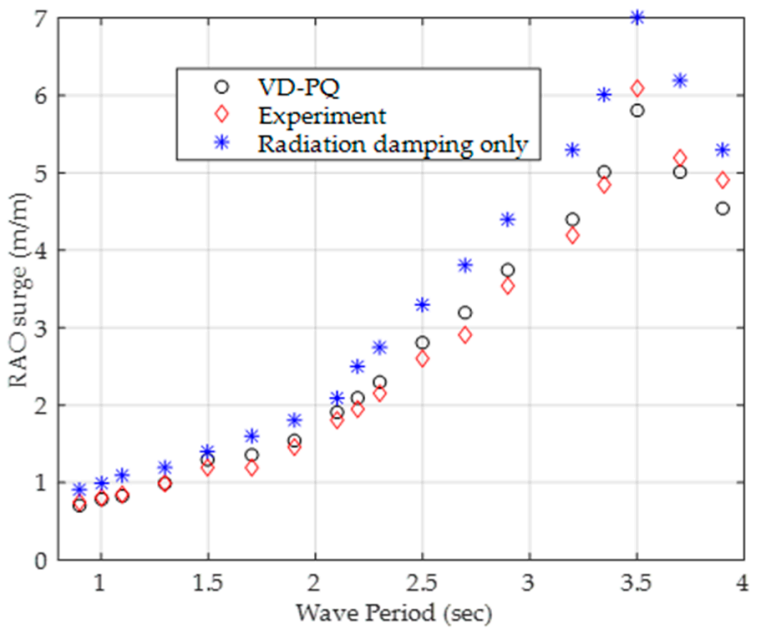

(b)

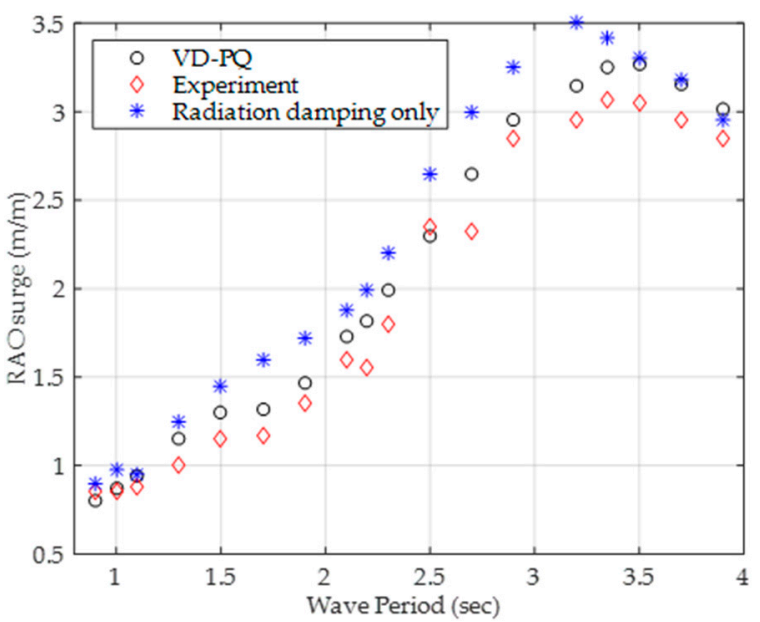

(c)

Figure 8. Comparison of surge motion of the examined WEC between experimental data and predictions with use of the VD-PQ viscous damping and with use of potential theory damping for (a) wave height equal to $12 \mathrm{~mm}$, (b) wave height equal to $25 \mathrm{~mm}$ and (c) wave height equal to $75 \mathrm{~mm}$. 


\section{Conclusions}

In the present paper, the boundary element method is coupled with results derived by a computational fluid dynamics model for the estimation and update of the viscous damping loads in every time-step of the analysis. A coupling numerical analysis method for addressing wave-structure interaction effects through a velocity-dependent viscous damping model (VD-PQ) in the time domain is developed and proposed. The coupling between the different models is realized through a Dynamic-link library. The numerical analysis method is applied for the case of a heaving type WEC, and comparisons are made against experimental data and relevant numerical analysis predictions. The basic findings of the research are highlighted below:

A method for accounting velocity-dependent viscous damping loads for every timestep of the analysis of a WEC in a boundary element model is developed and applied.

VD-PQ model provides very good accuracy compared to experimental data and, at the same time, low computational cost, especially for specific types of analysis (e.g., full long-term analysis).

The consideration of instantaneous velocity of the structure in estimating the viscous damping loads for every time-step of the solution of the equation of motion is important and should be accounted especially when the wave period is close to the natural period of motions of the structure.

Viscous damping loads should be appropriately addressed and accounted when dealing with the analysis and design of WECs.

The use of radiation damping, without any possible correction, for the analysis of WECs, may result to over-predictions in motions and consequently in the produced power of the WEC.

The combination and/or coupling of different numerical analysis models may result to increase of response calculation accuracy and decrease in computational cost.

The VD-PQ viscous damping model that is proposed in the present paper can be appropriately further developed (e.g., in the elastic degrees of freedom) for the case of WECs that hydroelasticity is important and dominates their response since the coupling of the structural deformations with CFD-based models is computationally expensive. Moreover, the proposed numerical analysis model will be further developed and assessed for the case of floating structures that are free to move in all six degrees of freedom and for the case of floating wind turbines. The aforementioned issues are prioritized as future work.

Funding: This research received no external funding.

Data Availability Statement: Data sharing not applicable.

Acknowledgments: The author would like to acknowledge the support from the Ministry of Energy, Commerce and Industry of the Republic of Cyprus through the funding provided for the establishment of the EMERGE (East Med Energy Research for Growth and Education) Research Center.

Conflicts of Interest: The author declares no conflict of interest.

\section{References}

1. WindEurope. Offshore Wind in Europe Key Trends and Statistics 2018. 2019. Available online: https://windeurope.org/wp-content/ uploads/files/about-wind/statistics/WindEurope-Annual-Offshore-Statistics-2019.pdf (accessed on 1 December 2020).

2. Jonkman, J.M.; Matha, D. Dynamics of offshore floating wind turbines-analysis of three concepts. Wind. Energy 2011, 14, 557-569. [CrossRef]

3. Zhang, L.; Shi, W.; Karimirad, M.; Michailides, C.; Jiang, Z. Second-order hydrodynamic effects on the response of three semisubmersible floating offshore wind turbines. Ocean Eng. 2020, 207, 107371. [CrossRef]

4. Falnes, J. Ocean Waves and Oscillating Systems; Cambridge University Press: Cambridge, UK, 2002.

5. Windt, C.; Davidson, J.; Rindwood, J.V. High-fidelity numerical modelling of ocean wave energy systems: A review of computational fluid dynamics-based numerical wave tanks. Renew. Sustain. Energy Rev. 2018, 93, 610-630. [CrossRef]

6. Faltinsen, O. Sea Loads on Ships and Offshore Structures; Cambridge University Press: Cambridge, UK, 1993.

7. Falnes, J. Radiation impedance matrix and optimum power absorption for interacting oscillators in surface waves. Appl. Ocean Res. 1980, 2, 75-80. [CrossRef] 
8. Falnes, J. Wave-energy conversion through relative motion between two single-mode oscillating bodies. J. Offshore Mech. Arct. Eng. 1999, 121, 32-38. [CrossRef]

9. Payne, G.S.; Taylor, J.M.; Bruce, T.; Parkin, P. Assessment of boundary-element method for modeling a free floating sloped wave energy device. Part 1: Numerical modeling. Ocean Eng. 2008, 38, 333-341. [CrossRef]

10. Gomes, R.; Henriques, J.; Gato, L.; Falcão, A. IPS twobody wave energy converter: Acceleration tube optimization. In Proceedings of the 20th International Offshore and Polar Engineering Conference, Beijing, China, 20-25 June 2010.

11. DNV. Recommended Practice-Environmental Conditions and Environmental Loads; DNV-RP-C205; DNV: Høvik, Norway, 2010.

12. Michailides, C.; Angelides, D.C. Optimization of a flexible floating structure for wave energy production and protection effectiveness. Eng. Struct. 2015, 85, 249-263. [CrossRef]

13. Muliawan, M.J.; Karimirad, M.; Moan, T. Dynamic response and power performance of a combined spar type floating wind turbine and coaxial floating wave energy converter. Renew. Energy 2013, 50, 47-57. [CrossRef]

14. Van der Vegt, J.J. Slinger Gedrag Van Schepen. In KIVI-Lecture on Seakeeping; KIVI-TV: Kivi, Iran, 1984.

15. Burmester, S.; Guilherme, V.; Gueydon, S.; Moctar, O. Investigation of a semi-submersible floating wind turbine in surge decay using CFD. Ship Technol. Res. 2020, 67, 2-14. [CrossRef]

16. Nematbakhsh, A.; Michailides, C.; Gao, Z.; Moan, T. Comparison of Experimental Data of a Moored Multibody Wave Energy Device With a Hybrid CFD and BIEM Numerical Analysis Framework. In Proceedings of the 34th International Conference on Ocean, Offshore and Arctic Engineering, St. John's, NL, Canada, 31 May-5 June 2015; Volume 9.

17. Schmitt, P.; Elsaesser, B. On the use of OpenFOAM to model oscillating wave surge converters. Ocean Eng. 2015, 108, 98-104. [CrossRef]

18. Windt, S.; Davidson, J.; Ransley, E.J.; Greaves, D.; Jakobsen, M.; Kramer, M.; Ringwood, J.V. Validation of a CFD-based numerical wave tank model for the power production assessment of the wavestar ocean wave energy converter. Renew. Energy 2020, 108, 2499-2516. [CrossRef]

19. Penalba, M.; Davidson, J.; Windt, C.; Ringwood, J.V. A high-fidelity wave-to-wire simulation platform for wave energy converters: Coupled numerical wave tank and power take-off models. Renew. Energy 2020, 226, 655-669. [CrossRef]

20. Windt, C.; Faedo, N.; García-Violini, D.; Peña-Sanchez, Y.; Davidson, J.; Ferri, F.; Ringwood, J.V. Validation of a CFD-Based Numerical Wave Tank Model of the 1/20th Scale Wavestar Wave Energy Converter. Fluids 2020, 5, 112. [CrossRef]

21. Benites-Munoz, D.; Huang, L.; Anderlini, E.; Marín-Lopez, J.R.; Thomas, G. Hydrodynamic Modelling of An Oscillating Wave Surge Converter Including Power Take-Off. J. Mar. Sci. Eng. 2020, 8, 771. [CrossRef]

22. Bhinder, M.A.; Mingham, C.G.; Causon, D.M.; Rahmati, M.T.; Aggidis, G.A.; Chaplin, R.V. A joint numerical and experimental study of a surging point absorbing wave energy converter (WRASPA). In Proceedings of the 28th International Conference on Ocean, Offshore and Arctic Engineering, Volume 4: Ocean Engineering; Ocean Renewable Energy, Ocean Space Utilization, Parts A and B., Honolulu, HI, USA, 31 May-5 June 2009; pp. 869-875.

23. Westphalen, J.; Greaves, D.M.; Raby, A.; Hu, Z.Z.; Causon, D.M.; Mingham, C.G.; Omidvar, P.; Stansby, P.K.; Rogers, B.D. Investigation of wave-structure interaction using state of the art CFD techniques. Open J. Fluid Dyn. 2014, 4, 18-43. [CrossRef]

24. Newman, J.N. Wave Effects on Deformable Bodies. Appl. Ocean Res. 1994, 6, 47-59. [CrossRef]

25. Lee, C.H.; Newman, J.N. An Assessment of Hydroelasticity for Very Large Hinged Vessels. J. Fluids Struct. 2000, 14, 957-970. [CrossRef]

26. Pathak, A.; Raessi, M. A 3D, fully Eulerian, VOF-based solver to study the interaction between two fluids and moving rigid bodies using the fictitious domain method. J. Comput. Phys. 2016, 311, 87-113. [CrossRef]

27. Patel, K.P.; Natarajan, G. A novel consistent and well-balanced algorithm for simulations of multiphase flows on unstructured grids. J. Comput. Phys. 2017, 350, 207-236. [CrossRef]

28. Nangia, N.; Griffith, B.E.; Patankar, N.A.; Bhalla, A.P.S. A robust incompressible Navier-Stokes solver for high density ratio multiphase flows. J. Comput. Phys. 2019, 390, 548-594. [CrossRef]

29. Nangia, N.; Patankar, N.A.; Bhalla, A.P.S. A DLM immersed boundary method based wave-structure interaction solver for high density ratio multiphase flows. J. Comput. Phys. 2019, 398, 108804. [CrossRef]

30. Dafnakis, P.; Bhalla, A.P.S.; Sirigu, S.A.; Bonfanti, M.; Bracco, G.; Mattiazzo, G. Comparison of wave-structure interaction dynamics of a submerged cylindrical point absorber with three degrees of freedom using potential flow and computational fluid dynamics models. Phys. Fluids 2020, 32, 093307. [CrossRef]

31. Bhalla, A.P.S.; Nangia, N.; Dafnakis, P.; Bracco, G.; Mattiazzo, G. Simulating water-entry/exit problems using Eulerian-Lagrangian and fully-Eulerian fictitious domain methods within the open-source IBAMR library. Appl. Ocean Res. 2020, 94, 101932. [CrossRef]

32. Nematbakhsh, A.; Olinger, D.J.; Tryggvason, G. A nonlinear computational model for floating wind turbines. J. Fluids Eng. 2013, 135, 121103. [CrossRef]

33. Nematbakhsh, A.; Olinger, D.J.; Tryggvason, G. Nonlinear simulation of a spar buoy floating wind turbine under extreme ocean conditions. J. Renew. Sustain. Energy 2014, 6, 033121. [CrossRef]

34. Karimirad, M.; Michailides, C.; Nematbakhsh, A. Offshore Mechanics: Structural and Fluid Dynamics for Recent Applications; John Wiley \& Sons: West Sussex, UK, 2018.

35. Cummins, W. The Impulse Response Function and Ship Motions; Navy Department, David Taylor Model Basin: Bethesda, MD, USA, 1962. 
36. Costello, R.; Padeletti, D.; Davidson, J.; Ringwood, J.V. Comparison of numerical simulations with experimental measurements for the response of a modified submerged horizontal cylinder moored in waves. In Proceedings of the 33rd International Conference on Ocean, Offshore and Arctic Engineering, 2014, Volume 9B: Ocean Renewable Energy, San Francisco, CA, USA, 8-13 June 2014.

37. Bhinder, M.A.; Murphy, J. Evaluation of the Viscous drag for a Domed Cylindrical Moored Wave Energy Converter. J. Mar. Sci. Eng. 2019, 7, 120. [CrossRef] 